Research Article

\title{
Train-Bridge Dynamic Behaviour of Long-Span Asymmetrical-Stiffness Cable-Stayed Bridge
}

\author{
Yuexing Wu $\mathbb{D}^{1},{ }^{1}$ Jianting Zhou $\mathbb{D}^{1},{ }^{1}$ Jinquan Zhang, ${ }^{2}$ Qiang Wen, ${ }^{1}$ and Xuan $\mathrm{Li}^{1}$ \\ ${ }^{1}$ School of Civil Engineering, Chongqing Jiaotong University, Chongqing, China \\ ${ }^{2}$ Research Institute of Highway, Ministry of Transport, Beijing, China \\ Correspondence should be addressed to Jianting Zhou; jtzhou@cqjtu.edu.cn
}

Received 31 May 2021; Accepted 25 October 2021; Published 18 November 2021

Academic Editor: Pedro Galvín

Copyright (c) 2021 Yuexing Wu et al. This is an open access article distributed under the Creative Commons Attribution License, which permits unrestricted use, distribution, and reproduction in any medium, provided the original work is properly cited.

Long-span cable-stayed bridge (LCB) with unequal-height towers is being designed and constructed in metro lines due to its better adaptability to environment and terrain conditions compared to traditional cable-stayed bridge with equal-height towers. However, the asymmetrical arrangement of towers leads to obvious nonuniformity of the structural stiffness along the longitudinal direction, which intensifies the wheel-rail coupled vibration behaviour, and affects the running safety of operating trains and ride comfort. Therefore, train-bridge dynamic behaviour of long-span asymmetrical-stiffness cable-stayed bridge is deeply investigated in this work. Primarily, considering the comprehensive index of frequency difference and modal assurance criterion (MAC), a nonlinear model updating technique (NMUT) based on penalty function theory is proposed, which can be used to optimize the bridge numerical model. Secondly, on the basis of the train-track-bridge dynamic interaction theory (TDIT), a traintrack-bridge coupled dynamic model (TCDM) is established. Finally, a LCB with unequal-height towers is applied as a case to illustrate the influence of asymmetrical stiffness on the train-track-bridge dynamic characteristics. Results show that the proposed NMUT is efficacious and practical. For the LCB with unequal-height towers, a significant difference between the bridge vibration at low tower location and that at high tower location appears. The vertical displacement difference of the main beam on both sides of the bridge increases with the distance from the observation point to the bridge tower increasing. The variation of acceleration difference on both sides of the bridge is influenced by the speed of the train and the position of the observation point simultaneously. In general, vibrations of the main beam at low tower location are larger than those at high tower location.

\section{Introduction}

During the past few years, due to the dynamic development of China's urban long-span railway bridges, cable-stayed bridges are widely built because of their unique and beautiful shape, small weight of bridge structure, excellent spanning ability, and perfect construction technology. Compared with the traditional cable-stayed bridge with equal-height towers, the cable-stayed bridge with unequal-height towers (UHTCB) has better adaptability to the environment and terrain conditions.

The UHTCB is an asymmetrical statically indeterminate structure. This asymmetrical arrangement of towers leads to great nonuniformity of the stiffness along the longitudinal direction, which results in additional stiffness irregularity
[1]. When the train passes through the UHTCB, the rail geometric irregularities and additional stiffness irregularities worsen the wheel-rail nonlinear contact state and then intensify the wheel-rail coupled vibration behaviour, which affects the ride comfort and running safety of operating trains. Moreover, the increased wheel-rail dynamic interaction (WDI) further amplifies the vibration of the cablestayed bridge system, resulting in the great difference in vibration, deformation, and stress states between the bridge at low tower location and that at high tower location, which eventually reduces the overall stability of the structure and affects the normal and safe service of the bridge. So it is very essential to investigate the vibration of the UHTCB.

Train-bridge coupled vibration (TCV) is a complicated interaction process, which has been studied for a very long 
time since it is a typical topic of railway dynamics [2, 3]. According to Zhai et al., the train, the track, and the bridge served as a whole dynamic system, with the purpose of offering an approach to analyse and assess the running safety of high-speed trains and the ride comfort. As a result, Zhai et al. established an integrated train-track-bridge dynamic interaction model and developed the software TTBSIM. Moreover, lots of field tests were carried out for validating this software $[4,5]$. Olmos et al. [6] developed an efficient nonlinear train-track-bridge dynamic interaction model to analyse the transverse dynamic response of high pier viaducts under the action of high-speed train. The influences of railway car-body flexibility on the dynamic performance of high-speed trains operating on bridges were investigated by Younesian et al. who found that the calculated ride comfort index can be influenced by the flexural mode shapes of the car-body structure dramatically particularly in the low frequency range [7]. Under the resonant excitations, an alternative analytical method was proposed by Yau et al. on the basis of an equivalent VBI model, providing insights of accounting for VBI impacts on short-span simply supported bridges in the railway by enabling a precise prediction of the additional amount of damping [8]. The models considering nonlinear wheel-rail contact forces were developed by Antolín et al. to research dynamic influences in the vehicles and in the bridge caused by the coupling and to analyse the dynamic interaction between bridges and high-speed trains [9]. In consideration of the vehicle-track-structure interaction, Melo et al. calibrated and validated a numerical model of a steel-concrete composite bridge [10]. Moreover, references [11-18] also investigated the train-track-bridge coupled interaction and proposed many beneficial conclusions. As known from existing studies, most works are focused on simple bridge structures such as continuous beam bridges or simply supported beam bridges, few researches on TCV involving complex bridges such as cable-stayed bridges, and even less on the UHTCB.

In the TCV simulation, the accuracy of the bridge FE model has an important influence on the accuracy of the simulation results. However, the FE model is different from the actual structure due to the influence of mesh generation, boundary conditions, and uncertainty of structural physical parameters [19]. Therefore, the FE model updating should be carried out to make it as close as possible to the actual structure, so as to conduct the vibration characteristics analysis of train-bridge system more accurately. Scholars worldwide have done a lot of researches on the model optimization and updating. Ren et al. [20] put forward an FE model updating technique in virtue of a response surface method in structural dynamics for civil engineering structures. Liu et al. [21] presented a method in virtue of fuzzy FE to take into account the impact of the uncertainties of the measured modal parameters on the updated FE model. Chakraborty et al. [22] made an attempt to explore the effectiveness of moving least-squares technique based on response surface method to update the FE model. Asgarieh et al. [23] proposed updating parameters of hysteretic material models assigned to substructures of a nonlinear FE model by minimizing an OF. Astroza et al. [24] advanced a hybrid global optimization algorithm by combining the unscented Kalman filter with the simulated annealing. Wang et al. [25] proposed a model updating tactic for localized nonlinear structures. These algorithms greatly improve the accuracy of the structural numerical model, but they are rarely used in long-span bridges, especially in the UHTCB.

Aiming at the complex train-bridge spatial coupled vibration problem caused by asymmetrical stiffness of the UHTCB, an NMUT is proposed, and a refined TCDM is established on the basis of the TDIT. A long-span UHTCB is applied as a case to illustrate the influence of asymmetrical stiffness on the train-bridge system dynamic behaviour.

\section{Model Optimization Based on NMUT}

When studying train-bridge dynamic behaviour of the LCB, remarkable discrepancies in respect of the mechanical and dynamic characteristics between the numerical model and the actual structure can be in existence because of the influence of mesh division, boundary conditions, and uncertainties related to physical parameters and assumptions. Therefore, it is considered very necessary to improve the accuracy of the FE model. Before conducting the study on the train-bridge dynamic characteristics of the LCB, the natural vibration characteristics of the LCB are analysed first. By updating the parameters of the FE model, the natural vibration characteristics of the model are as close as possible to the actual structure, to ensure that the subsequent study of the dynamic characteristics of the train and bridge is more meaningful. To calculate and analyse the TCV more accurately, considering the comprehensive index of frequency difference and MAC, an NMUT based on penalty function theory is proposed to optimize the bridge numerical model. The flow chart of updating the bridge model is shown in Figure 1.

2.1. Establishment of Initial Bridge Model. In virtue of the FEM, the bridge model is established, and dynamic equation can be expressed by

$$
\mathbf{M}_{b} \ddot{\mathbf{X}}_{b}+\mathbf{C}_{b} \dot{\mathbf{X}}_{b}+\mathbf{K}_{b} \mathbf{X}_{b}=\mathbf{F}_{b}
$$

where $\mathbf{M}_{b} / \mathbf{C}_{b} / \mathbf{K}_{b}$ are the mass/damping/stiffness matrices of the bridge system; $\mathbf{X}_{b} / \dot{X}_{b} / \ddot{X}_{b}$ are the displacement/velocity/ acceleration vectors of the bridge system; $\mathbf{F}_{b}$ is the force vector for the bridge system.

According to (1), the free vibration motion equation of the undamped structural system is established:

$$
[\mathbf{M}]\{\ddot{u}\}+[\mathbf{K}]\{\mathbf{u}\}=\{0\} .
$$

Under specific initial conditions, the simple harmonic vibration equation of the system at the same frequency is established:

$$
\{\mathbf{u}\}=\{\boldsymbol{\phi}\} \sin (\omega t+\theta) .
$$

Taking the derivative of (3) and substitute it into (2) and noticing the arbitrariness of $\sin (\omega t+\theta)$, there is 


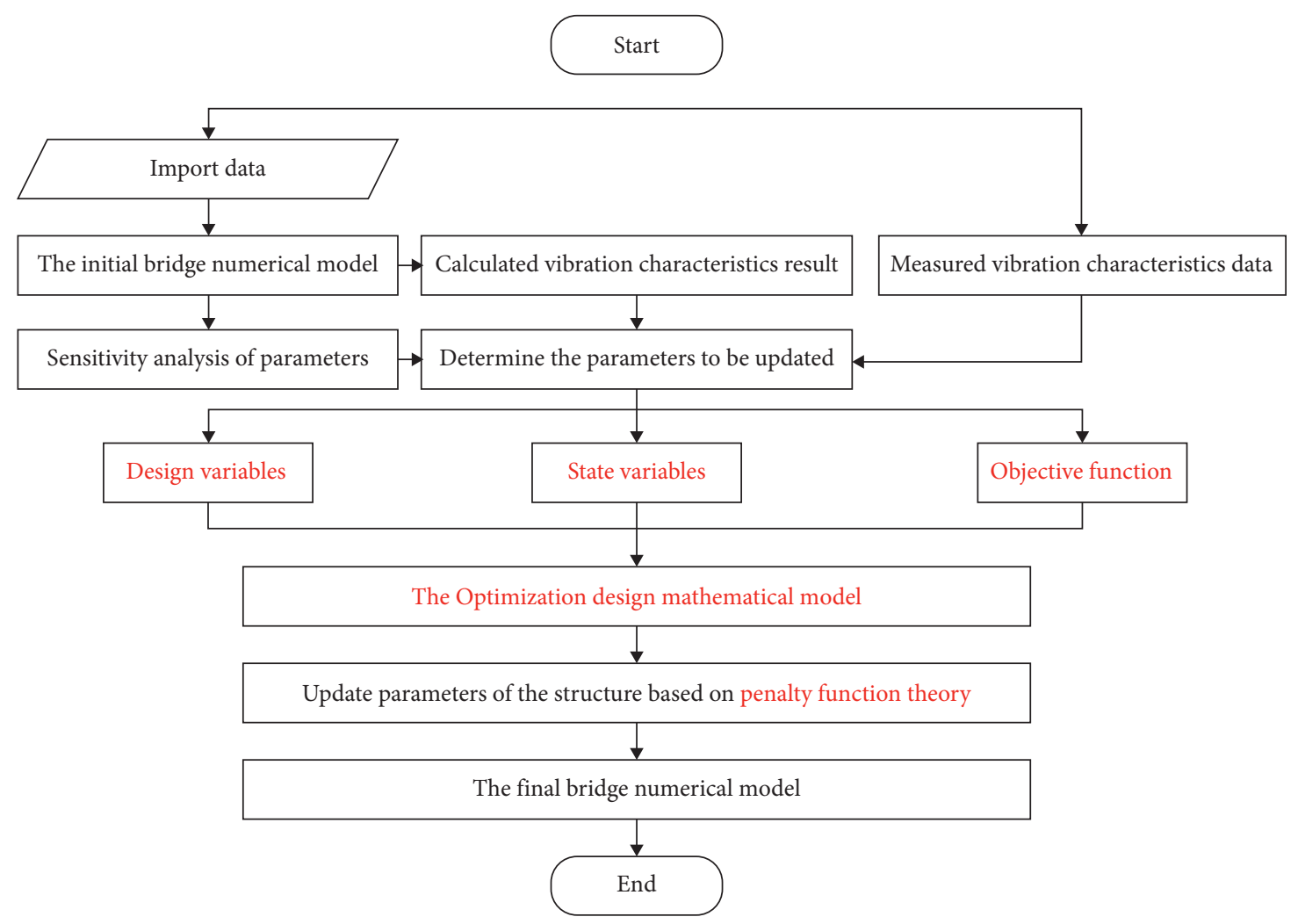

FIgUre 1: The flow chart of updating the bridge model.

$$
\left([\mathbf{K}]-\omega^{2}[\mathbf{M}]\right)\{\boldsymbol{\phi}\}=\{0\} .
$$

Then, the characteristic equation of the system is obtained as

$$
\left|[\mathbf{K}]-\omega^{2}[\mathbf{M}]\right|=0 .
$$

The root $\omega_{i}^{2}(i=1,2, \ldots, N)$ of (5) is called the $i$ th eigenvalue. $\omega_{i}(i=1,2, \ldots, N)$ is called the $i$ th order natural circle frequency $(\mathrm{rad} / \mathrm{s})$. If the system has $N$ degrees of freedom, the system has $N$ order natural circle frequency $\omega_{i}$ and $N$ order mode shapes $\{\phi\}_{i}(i=1,2, \ldots, N)$. The relationship between natural circle frequency $\omega_{i}$ and natural frequency $f_{i}$ (cycle/s or $\mathrm{Hz}$ ) and natural period of vibration $T_{i}(s)$ is shown in

$$
\omega_{i}=2 \pi f_{i}=\frac{2 \pi}{T_{i}} .
$$

The ith eigenvector $\{\phi\}_{i}=\left[\phi_{1}^{(i)}, \phi_{2}^{(i)}, \ldots, \phi_{N}^{(i)}\right]^{\mathrm{T}}(i=1,2$, $\ldots, N)$ corresponding to $\omega_{i}$ that satisfies (4) is called the $i$ th order mode shapes.

\subsection{Establishment of Optimization Model for Updating.} The nonlinear updating of model parameters is essentially the mathematical optimization design of the model. The core idea of optimization design is to get the minimum value of the objective function by establishing an optimization model and using an optimization algorithm under constraint conditions. This process involves design variables (DVs), state variables (SVs), and objective function (OF). DVs are independent variables, which are usually the geometric dimensions, structural physical parameters of the research object. They are the optimization objects and they change constantly in the whole optimization process. SVs are not independent variables, which change with the change of DVs. SVs are functions of DVs and constraint conditions for optimization design. In general, the existence of SVs is to ensure that the optimization has a clear physical significance. The $\mathrm{OF}$ is the minimization variable in optimization design. It is the function of DVs and will change with the change of DVs too. It is the criterion to determine the optimization design scheme. DVs, SVs, and OF are described in the following sections in turn.

2.2.1. Design Variable. The selection of appropriate DVs is crucial to the success of model updating. It is considered very necessary to conduct the sensitivity analysis of the parameters, which selects the appropriate DVs and improves the updating efficiency. In addition, the natural vibration frequency is only related to the stiffness matrix [K] and mass matrix $[\mathbf{M}]$ of the system according to (5). For nonlinear updating of bridge model, the sensitive parameters such as elasticity modulus, inertia moment, and density of each component of the structure can be selected as DVs. The number of DVs and their upper and lower limits are determined comprehensively by the requirements of model updating accuracy and calculation efficiency, and the DVs can be expressed as 


$$
\left.\begin{array}{l}
\mathbf{x}=\left[x_{1}, x_{2}, \ldots, x_{n}\right]^{T} \\
\underline{x}_{i} \leq x_{i} \leq \bar{x}_{i}
\end{array}\right\}
$$

2.2.2. State Variable. The dynamic analysis should focus on the structural frequency and mode shape. The absolute value of the difference between $f_{i}$ (the analytical frequency) and $f_{i}^{\prime}$ (the experimental frequency) is written as $\left|f_{i}-f_{i}^{\prime}\right|$. The ratio $\left(\left|f_{i}-f_{i}^{\prime}\right| / f_{i}^{\prime}\right)$ is selected as the constraint condition, which is required less than or equal to the upper limit value $e_{\mathrm{f}}$. The constraint condition can be expressed as

$$
0 \leq \frac{\left|f_{i}-f_{i}^{\prime}\right|}{f_{i}^{\prime}} \leq e_{f}
$$

As a quantitative correlation criterion in statistics, the $M A C$ is adopted in mode pairing to correlate the results between the analytical mode shape and the experimental mode shape [26]. The MAC can be calculated as

$$
\mathrm{MAC}_{i}=\frac{\left[\{\boldsymbol{\phi}\}_{i}^{T}\{\boldsymbol{\phi}\}_{i}^{\prime}\right]^{2}}{\{\boldsymbol{\phi}\}_{i}^{T}\{\boldsymbol{\phi}\}_{i}\{\boldsymbol{\phi}\}_{i}^{\prime T}\{\boldsymbol{\phi}\}_{i}^{\prime}}
$$

where $M A C_{i}$ is the $i$ th order modal assurance criterion, $\{\phi\}_{i} /\{\phi\}_{i}^{\prime}$ are analytical/experimental mode shape vector, and $i$ is modal order. The MAC value is between 0 and 1 . Generally, if the $M A C$ value is greater than 0.7 , it is considered that the two sets of mode shapes can match to a certain extent [26]. The closer the $M A C$ value is to 1 , the higher the correlation between the two sets of mode vectors is. Usually, the correlation degree is higher at lower modes, and the higher the order is, the more difficult it is to pair the modes. Therefore, when the MAC is used as the SV, the lower limit $e_{\mathrm{mac}}$ of the $M A C$ can be set slightly higher at lower modes, while the lower limit $e_{\mathrm{mac}}$ of the $M A C$ should be lowered at higher modes. The constraint condition can be expressed as

$$
e_{\mathrm{mac}} \leq M A C_{i} \leq 1
$$

2.2.3. Objective Function. The OF can comprehensively consider the minimum sum of the two parts. Part one is the frequency difference between the analytical frequency and the experimental frequency. Part two is the $M A C_{i}$. The $\mathrm{OF}$ can be expressed as

$$
\begin{aligned}
g(\mathbf{x}) & =\sum_{i=1}^{n} \alpha_{i}\left(\frac{f_{i}-f_{i}^{\prime}}{f_{i}^{\prime}}\right)^{2}+\sum_{i=1}^{n} \beta_{i}\left(\frac{1-\sqrt{M A C_{i}}}{M A C_{i}}\right)^{2} \\
& =g\left(x_{1}, x_{2}, \ldots, x_{n}\right),
\end{aligned}
$$

where $\alpha_{i}$ and $\beta_{i}$ are weight.

2.2.4. Optimization Model for Updating. Once the DVs, SVs, and $\mathrm{OF}$ are determined, the optimization model for updating can be established. The essence of the optimization model is to solve the minimum value of a function under certain constraints. The optimization model for updating can be simplified as

$$
\left.\begin{array}{ll}
\text { Minimize } & g(\mathbf{x}) \\
\text { Subject to } & \underline{s}_{i} \leq s_{i}(\mathbf{x}) \leq \bar{s}_{i}, \quad i=1,2, \ldots, m \\
& \underline{x}_{j} \leq x_{j} \leq \bar{x}_{j}, \quad j=1,2, \ldots, n
\end{array}\right\},
$$

where $\underline{x}_{j}$ and $\bar{x}_{j}$ are the lower and upper limits on the DVs, respectively, and $n$ is the number of the DV; $\underline{s}_{i}$ and $\bar{s}_{j}$ are the lower and upper limits on the SVs, respectively, and $m$ is the number of the SV.

\subsection{Model Optimization Algorithm Based on Penalty Function} Theory. According to (12), the optimization model for updating established in this work is a constrained optimization problem. The penalty function method is used to convert the constrained optimization problem into an unconstrained optimization problem [27]. Furthermore, the partial derivatives of the dependent variables (OF and SV) to the DVs are used to determine the search direction, and the optimization results are obtained to minimize the true FE results. The steepest descent method and conjugate direction method are used in the iteration process. Each iteration consists of a series of subiterations, and an iteration is equivalent to multiple analysis cycles to achieve higher optimization accuracy. The constrained problem is written as

$$
F_{0}\left(\mathbf{x}, q_{k}\right)=\frac{g(\mathbf{x})}{g_{0}}+q_{k} \sum_{i=1}^{n} P_{x}\left(x_{i}\right)+q_{k} \sum_{i=1}^{m} P_{s}\left(s_{i}\right),
$$

where $F_{0}$ is the unconstrained $\mathrm{OF}$, which is dimensionless; $g_{0}$ is the reference function weight, which is adopted to adjust the ratio between the various functions; $q_{k}$ is the response surface parameter of the optimization function, which can improve the optimization accuracy; $P_{x}$ is a penalty function for $\mathrm{DV}$ constraints ; $P_{s}$ is a penalty function for state variable constraints ; $k$ is the number of iteration indicator.

The function $F_{0}$ is expressed as the sum of two functions, which can be defined as

$$
\left.\begin{array}{l}
F_{g}(\mathbf{x})=\frac{g(\mathbf{x})}{g_{0}} \\
F_{q}\left(\mathbf{x}, q_{k}\right)=q_{k} \sum_{i=1}^{n} P\left(x_{i}\right)+q_{k} \sum_{i=1}^{m} P\left(s_{i}\right)
\end{array}\right\} .
$$

Then, $F_{0}$ can be replaced as

$$
F_{0}(\mathbf{x}, q)=F_{g}(\mathbf{x})+F_{q}(\mathbf{x}, q)
$$

where the functions $F_{g}$ and $F_{q}$ are related to the OF and penalty function, respectively.

The basic idea of the unconstrained optimization method is to select a favorable search direction at an approximate point and search in one dimension along this direction to obtain a new approximation point. Then the same process is performed for the new point, so that 
iteration is repeated until the predetermined accuracy requirements are met.

For each iteration $(j)$, a search vector in one direction is defined, and the next iteration is shown as

$$
\left.\begin{array}{l}
\mathbf{x}^{(j+1)}=\mathbf{x}^{(j)}+\alpha^{(j)} \mathbf{d}^{(j)} \\
\mathbf{d}^{(0)}=-\nabla F\left(\mathbf{x}^{(0)}, q\right)=\mathbf{d}_{g}^{(0)}+\mathbf{d}_{q}^{(0)}
\end{array}\right\}
$$

where the line search parameter $\alpha^{(j)}$ is the minimum value of the function $F$ taken in the $\mathbf{d}^{(j)}$ direction.

In the initial iteration step, the search method is the steepest descent method, and then the conjugate direction method is used for calculation:

$$
\begin{aligned}
\mathbf{d}^{(j)} & =-\nabla F\left(\mathbf{x}^{(j)}, q_{k}\right)+\beta^{(j-1)} \mathbf{d}^{(j-1)}, \\
\beta^{(j-1)} & =\frac{\left[\nabla F\left(\mathbf{x}^{(j)}, q\right)-\nabla F\left(\mathbf{x}^{(j-1)}, q\right)\right]^{\mathrm{T}} \nabla F\left(\mathbf{x}^{(j)}, q\right)}{\left|\nabla F\left(\mathbf{x}^{(j-1)}, q\right)\right|^{2}},
\end{aligned}
$$

where $\beta^{(j-1)}$ is the conjugate gradient parameter [27].

When the following equations are satisfied, the iteration converges.

$$
\left.\begin{array}{l}
\left|g^{(j)}-g^{(j-1)}\right| \leq e_{g} \\
\left|g^{(j)}-g^{(b)}\right| \leq e_{g}
\end{array}\right\}
$$

where $g^{(j)}$ and $g^{(j-1)}$ are the results of the $j$ th iteration and the $(j-1)$ th iteration of the OF, respectively, $g^{(b)}$ is the current optimal OF value, and $e_{g}$ is the OF tolerance.

2.4. Establishment of Final Bridge Model. Based on the NMUT, the structural geometry dimensions, physical parameters, mass matrix, damping matrix, and stiffness matrix of the initial bridge model are updated several times to form the final bridge model. Equation (1) can be written as

$$
\mathbf{M}_{b}^{\prime} \ddot{\mathbf{X}}_{b}+\mathbf{C}_{b}^{\prime} \dot{\mathbf{X}}_{b}+\mathbf{K}_{b}^{\prime} \mathbf{X}_{b}=\mathbf{F}_{b}
$$

\section{Train-Track-Bridge Coupled Dynamic Model}

On the basis of the TDIT, the TCDM is established, which is composed of three submodels, including the train, the track, and the bridge, as shown in Figure 2. The train, the track, and the bridge form a whole dynamic system, where the track and bridge are linked through the track-bridge interaction (TBI) while the train and the track are coupled by the WDI. The train submodel is established on the basis of the multibody dynamics theory. The track submodel and the bridge submodel are established by adopting the FEM [5].

3.1. Train Submodel. The train is regarded as a sequence of vehicles, and each vehicle is an MDOF system. It consists of the car body, two bogies, four wheelsets, and springdamping suspension devices. The vehicle is generally considered as a whole mass to analyse the dynamic impact of its vibration on the bridge in the dynamic interaction study of the train-track-bridge system [5]. Therefore, to simplify the

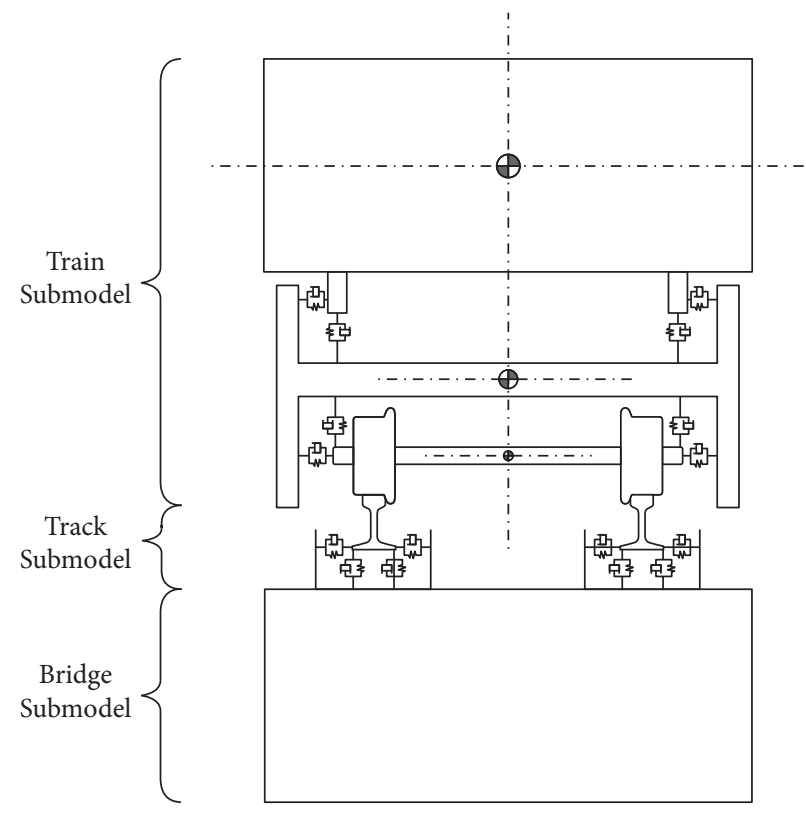

FIgURe 2: Train-track-bridge coupled dynamic model.

analysis process, the following assumptions of the vehicle model are used to analyse the train-track-bridge coupled vibration model:

(i) The car body, bogie, and wheelset are all rigid bodies; i.e., the elastic deformation of the car body, bogie, and wheelset during vibration is neglected.

(ii) The connection of spring and damper between car body and bogie is called "secondary suspension device", while that between bogie and wheelset is called "primary suspension device". The primary spring and secondary spring can be either linear or nonlinear; while the primary damper and secondary damper can be either viscous and frictional.

(iii) Along the longitudinal direction of the vehicle, the vibration of car body, bogie, and wheelset is not considered.

(iv) Each car body and each bogie only consider two DOFs, including the vertical motion and the pitch motion, and each wheelset considers one DOF, i.e., the vertical motion. The primary and secondary suspensions are modeled as springs and dampers. Therefore, for a two-series four-axle vehicle with two bogies, the calculated degree of freedom is ten.

The vehicle equation can be obtained by applying $\mathrm{D}^{\prime}$ Alembert principle to each rigid body. Eventually, the dynamic model of train submodel can be expressed as

$$
\mathbf{M}_{v} \ddot{\mathbf{X}}_{v}+\mathbf{C}_{v} \dot{\mathbf{X}}_{v}+\mathbf{K}_{v} \mathbf{X}_{v}=\mathbf{P}_{v}
$$

where $\mathbf{M}_{v} / \mathbf{C}_{v} / \mathbf{K}_{v}$ are the mass/damping/stiffness matrices of the vehicle system; $\mathbf{X}_{v} / \dot{X}_{v} / \ddot{X}_{v}$ are the displacement/velocity/ acceleration vectors of the vehicle system; $\mathbf{P}_{v}$ is the load vector of the vehicle system. 
3.2. Track Submodel. The ballastless track is generally used for traffic lines on urban rail transit bridges. The rail is simulated as a continuous beam, which is supported by fasteners discretely, and only one DOF of the rail is taken into consideration, i.e., the vertical motion [5]. The dynamic model of track submodel is expressed as

$$
\mathbf{M}_{t} \ddot{\mathbf{X}}_{t}+\mathbf{C}_{t} \dot{\mathbf{X}}_{t}+\mathbf{K}_{t} \mathbf{X}_{t}=\mathbf{P}_{t} \text {, }
$$

where $\mathbf{M}_{t} / \mathbf{C}_{t} / \mathbf{K}_{t}$ are the mass/damping/stiffness matrices of the track system $; \mathbf{X}_{t} / \dot{X}_{t} / \ddot{X}_{t}$ are the displacement/velocity/ acceleration vectors of the track system; $\mathbf{P}_{t}$ is the load vector of the track system.

3.3. Bridge Submodel. Since the modeling process of the bridge submodel has been described in Chapter 2 (see (19)), it will not be repeated here.

3.4. Dynamic Interaction between Wheel and Rail. The Hertz nonlinear elastic theory is used in order to describe the WDI [5], which is written as

$$
P(t)=\left[\frac{1}{G}\left(Z_{w}(x, t)-Z_{r}(x, t)-Z_{0}(x)\right)\right]^{3 / 2},
$$

where $P(t)$ is wheel-rail force; $G$ is the contact constant of wheel and rail; $R$ is the radius of wheel; $Z_{w} / Z_{r}$ are the wheel/ rail displacement; $Z_{0}$ is rail random irregularity.

3.5. Train-Track-Bridge Coupled Dynamic Model. The following equations are obtained by combining the motion equations (19), (20), and (21).

$$
\left\{\begin{array}{l}
\mathbf{M}_{v} \ddot{\mathbf{X}}_{v}+\mathbf{C}_{v} \dot{\mathbf{X}}_{v}+\mathbf{K}_{v} \mathbf{X}_{v}=\mathbf{P}_{v}, \\
\mathbf{M}_{t} \ddot{\mathbf{X}}_{t}+\mathbf{C}_{t} \dot{\mathbf{X}}_{t}+\mathbf{K}_{t} \mathbf{X}_{t}=\mathbf{P}_{t}, \\
\mathbf{M}_{b}^{\prime} \ddot{\mathbf{X}}_{b}+\mathbf{C}_{b}^{\prime} \dot{\mathbf{X}}_{b}+\mathbf{K}_{b}^{\prime} \mathbf{X}_{b}=\mathbf{F}_{b} .
\end{array}\right.
$$

In the process of the train crossing the bridge, the train, the track, and the bridge form a whole vibration system. The three subsystems are spatially coupled by the WDI and the TBI. In other words, the load vectors at the right side of the equations above are coupled with each other, and the vibration of the large system satisfies the equilibrium condition of force and the deformation compatibility condition at any time. The Newmark- $\beta$ numerical integration method can be chosen to solve (23) of the train-track-bridge model [5].

\section{Investigation on Train-Bridge Dynamic Behaviour of Long-Span UHTCB}

4.1. Parameters Adopted in Calculation. This section determines the parameters of the train-track-bridge system.

The calculated train is Type-A metro vehicle; the key dynamic parameters of the train are listed in Table 1.

The double-block ballastless track, whose detailed dynamic parameters can be referred to in [28], is applied in this investigation.
TABLE 1: Key dynamic parameters of the train.

\begin{tabular}{lcc}
\hline Item & Value & Unit \\
\hline Distance between bogie centers & 15.7 & $\mathrm{~m}$ \\
Bogie wheelbase & 2.5 & $\mathrm{~m}$ \\
Wheel rolling circle diameter & 0.42 & $\mathrm{~m}$ \\
Car body mass & 42.51 & $\mathrm{t}$ \\
Bogie frame mass & 2.8 & $\mathrm{t}$ \\
Wheelset mass & 1.6 & $\mathrm{t}$ \\
Inertia moment of car body & 1985.11 & $\mathrm{t} . \mathrm{m}^{2}$ \\
Inertia moment of bogie frame & 0.644 & $\mathrm{t} . \mathrm{m}^{2}$ \\
Inertia moment of wheelset & 0.118 & $\mathrm{t} . \mathrm{m}^{2}$ \\
Primary suspension stiffness & 1.23 & $\mathrm{MN} / \mathrm{m}$ \\
Secondary suspension stiffness & 0.415 & $\mathrm{MN} / \mathrm{m}$ \\
\hline
\end{tabular}

A long-span UHTCB is selected as a case study to illustrate its vehicle-bridge dynamic behaviour. The bridge is the main span $480 \mathrm{~m}$ semifloating system cable-stayed bridge, and the span layout of the main bridge is $34.5+180.5+480+215.5+94.5=1005 \mathrm{~m}$, as shown in Figure 3. The main beam of the bridge adopts the form of a separated double steel box section with a beam height of $3.3 \mathrm{~m}$ and a deck width of $21.8 \mathrm{~m}$, as shown in Figure 4 . The bridge tower adopts the form of gate type, the height of the low tower is $160 \mathrm{~m}$, while the height of the high tower is $229 \mathrm{~m}$, as shown in Figure 5, and the height difference between the high tower and the low tower is $69 \mathrm{~m}$. The pier is in the form of a column pier, and the foundation is a pile group foundation. Galvanized high strength and low relaxation parallel steel wire whose diameter is $7.0 \mathrm{~mm}$ is used for stay cables. 54 pairs are set at the high tower side while 32 pairs at the low tower side.

With the purpose of magnifying the dynamic response difference between the bridge at the low tower location and that at the high tower location as far as possible, the track irregularity is not considered when the train runs the bridge.

When studying the dynamic behaviour of train-bridge system, the representative calculation conditions are selected, as listed in Table 2.

4.2. Nonlinear Updating of the Bridge Model. The bridge model optimization design is carried out based on the NMUT mentioned above. Nine DVs are selected for the updating of the bridge model, respectively, represented by parameters $x_{1}$ to $x_{9}$, as listed in Table 3. In this paper, the investigation on the train-bridge dynamic behaviour of the cable-stayed bridge mainly focuses on the main beam structure, so the first four vertical vibration modes and the first two lateral vibration modes of the main beam in the natural vibration characteristics of the bridge are selected as the constraint objects. The ratio $\left(\left|f_{i}-f_{i}^{\prime}\right| / f_{i}^{\prime}\right)$ and the $M A C_{i}$ of the six modes are taken as the SVs, which are expressed by the parameters $s_{1}$ to $s_{12}$, respectively, as listed in Table 4 , and the OF is illustrated in Section 2.2.3. In addition, the upper and lower limits of DVs and SVs can be referred to in [26], as well as the real condition of engineering simultaneously.

After 35 iterations of updating, the modal analysis results of the final updated model are highly in agreement with the experimental modal results. The iterative process of the OF 


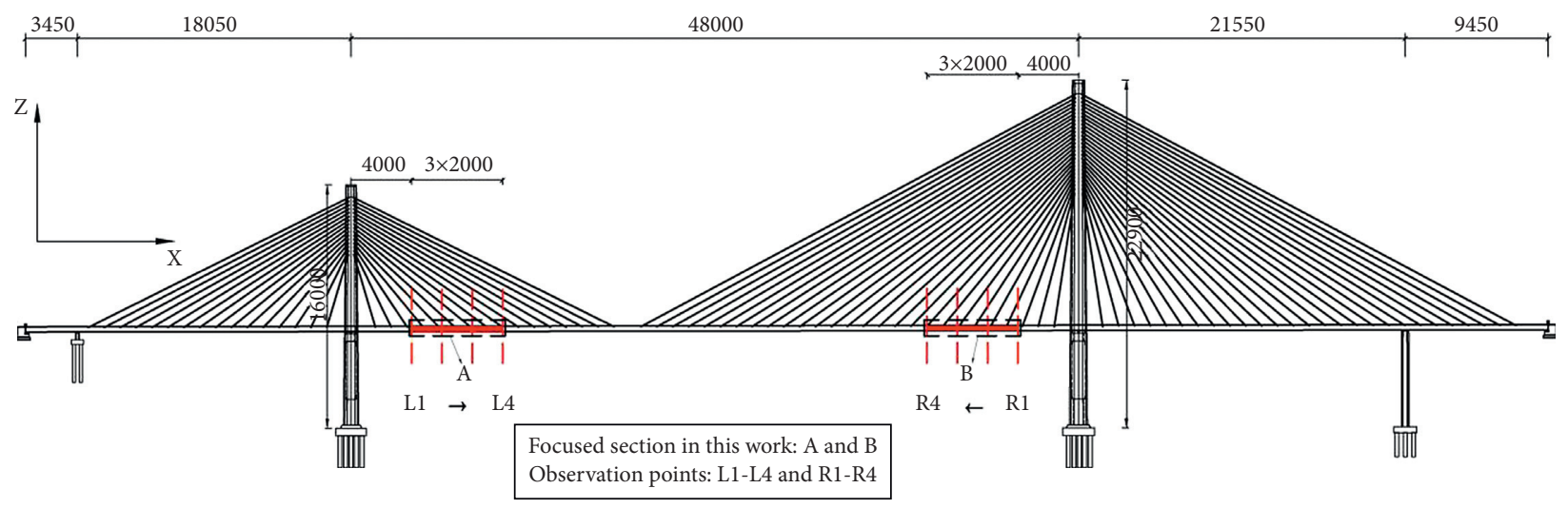

FIgURE 3: Bridge structural layout (unit: $\mathrm{cm}$ ).

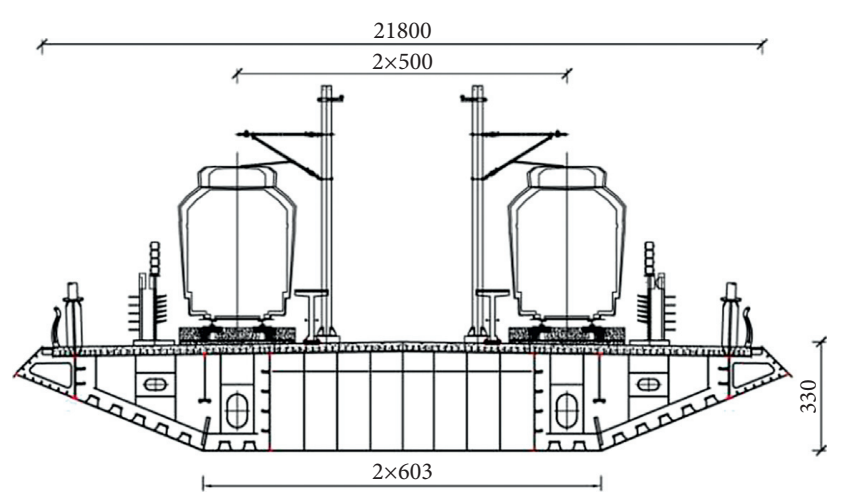

Figure 4: Cross-sectional layout (unit: $\mathrm{cm}$ ).

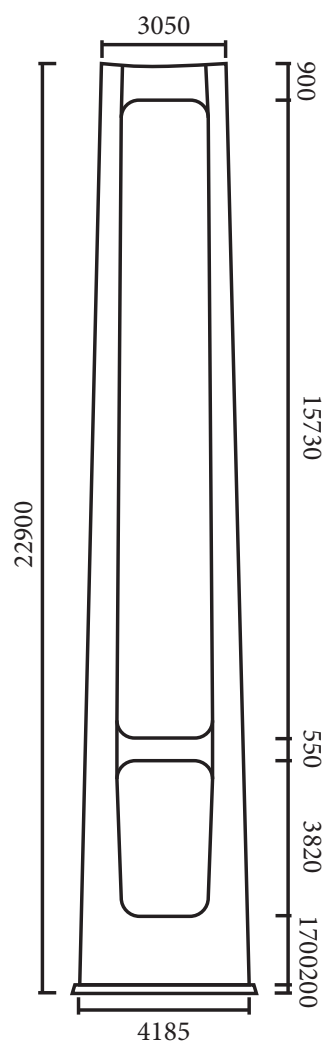

FIGURE 5: Layout of bridge tower (unit: $\mathrm{cm}$ ). value is shown in Figure 6, and the variations of each SV before and after the updating are illustrated in Figures 7 and 8 , respectively.

It can be seen that the frequency difference is greatly reduced with the maximum reduction of $8.7 \%$, and the frequency difference after the nonlinear updating is within $3.5 \%$. The modal assurance criterion of each mode is also significantly improved. In addition, the OF value is reduced from 0.0393 to 0.0073 with a decrease of $81.3 \%$. In conclusion, the optimization effect is remarkable, which can be considered as a successful model updating. Due to length limitations of the paper, only the main vibration modes are given here, as illustrated in Figure 9.

As seen from the results, the first-order natural vibration frequency of the bridge is $0.208 \mathrm{~Hz}$, and the period is $4.81 \mathrm{~s}$, which is less than $5 \mathrm{~s}$, indicating that the bridge belongs to the short-period category and the overall stiffness of the bridge is higher. The first-order lateral vibration mode of the main beam appears before the first-order vertical vibration mode of the main beam, indicating that the lateral stiffness of the main beam is smaller than the vertical stiffness. The lateral stiffness is also the key to the bridge design, which conforms to the general law of railway cable-stayed bridge in metro lines. The first-order vertical/lateral vibration mode shape is in the form of half-wave, and the maximum displacement value of the bridge is located near the midspan of the main span, which should be worthy of being paid more attention to in bridge design. High tower first-order lateral vibration mode occurs before the low tower first-order lateral vibration mode, because the high tower is taller than the low tower and its lateral stiffness is lower.

4.3. Influence of Stiffness Asymmetry of the Cable-Stayed Bridge on Vibration of the Train System. The asymmetrical arrangement of UHTCB results in greater stiffness inhomogeneity along the longitudinal direction, which leads to the additional irregularity of stiffness. When the train runs through the bridge, the additional irregularity of stiffness will aggravate the coupled vibration of wheel and rail, which will greatly influence the safety and stability of the train. Therefore, in this section, the dynamic response difference of the vehicle between Section-A and Section-B during train 
TABle 2: Calculation conditions.

\begin{tabular}{lc}
\hline Item & Specification \\
\hline Train & Type-A train with 8 vehicles \\
Speed & $60 / 80 / 100 / 120 \mathrm{~km} / \mathrm{h}$ \\
Running direction & From the low tower side to the high tower side \\
$\begin{array}{l}\text { Focused section } \\
\text { Observation points }\end{array}$ & The location on the main span, which is $40 \mathrm{~m}-100 \mathrm{~m}$ away from the tower (Section-A and Section-B) \\
\hline
\end{tabular}

TABle 3: Design variables.

\begin{tabular}{lccc}
\hline Parameter & Specification & Allowed decrease (\%) & Allowed increase (\%) \\
\hline$x_{1}$ & Elasticity modulus of main beam & -25 & 25 \\
$x_{2}$ & Density of main beam & -25 & 25 \\
$x_{3}$ & Inertia moment of main beam around $Y$-axis & -25 & 25 \\
$x_{4}$ & Inertia moment of main beam around $Z$-axis & -25 & 25 \\
$x_{5}$ & Elasticity modulus of tower & -25 & 25 \\
$x_{6}$ & Density of tower & -25 & 25 \\
$x_{7}$ & Inertia moment of tower around $Y$-axis & -25 & 25 \\
$x_{8}$ & Inertia moment of tower around $X$-axis & -25 & 25 \\
$x_{9}$ & Elasticity modulus of stay-cable & -25 & 25 \\
\hline
\end{tabular}

TABLE 4: State variables.

\begin{tabular}{|c|c|c|c|c|}
\hline Parameter & & Specification & Lower limit & Upper limit \\
\hline$s_{1}$ & \multirow{6}{*}{$\left(\left|f_{i}-f_{i}^{\prime}\right| / f_{i}^{\prime}\right)$} & 1st-order vertical vibration mode & 0 & $3.5 \%$ \\
\hline$s_{2}$ & & 2nd-order vertical vibration mode & 0 & $3.5 \%$ \\
\hline$s_{3}$ & & 3 rd-order vertical vibration mode & 0 & $3.5 \%$ \\
\hline$s_{4}$ & & 4 th-order vertical vibration mode & 0 & $3.5 \%$ \\
\hline$s_{5}$ & & 1st-order lateral vibration mode & 0 & $3.5 \%$ \\
\hline$s_{6}$ & & 2nd-order lateral vibration mode & 0 & $3.5 \%$ \\
\hline$s_{7}$ & \multirow{6}{*}{$M A C_{i}$} & 1st-order vertical vibration mode & 0.95 & 1 \\
\hline$s_{8}$ & & 2 nd-order vertical vibration mode & 0.95 & 1 \\
\hline$s_{9}$ & & 3 rd-order vertical vibration mode & 0.85 & 1 \\
\hline$s_{10}$ & & 4 th-order vertical vibration mode & 0.85 & 1 \\
\hline$s_{11}$ & & 1st-order lateral vibration mode & 0.95 & 1 \\
\hline$s_{12}$ & & 2nd-order lateral vibration mode & 0.95 & 1 \\
\hline
\end{tabular}

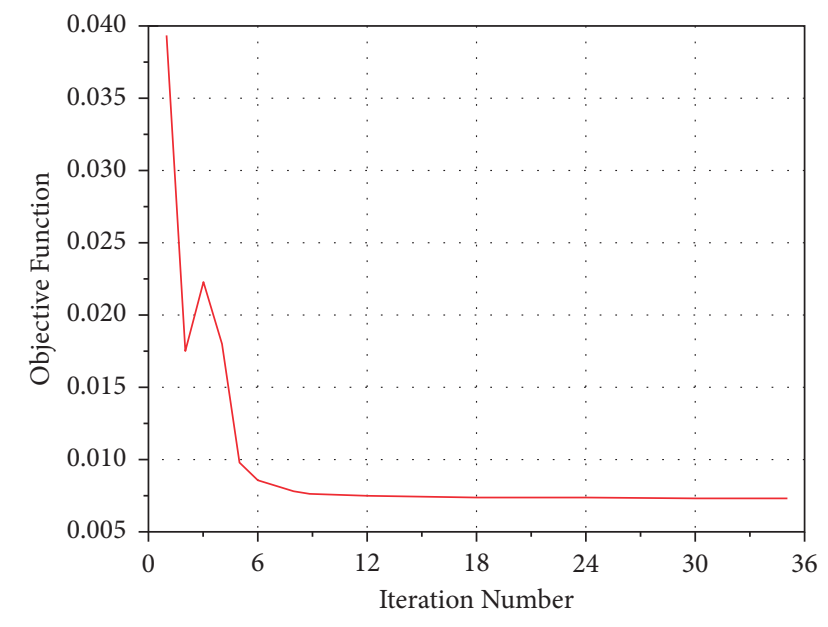

FIgURE 6: Variation of the objective function value.

crossing the bridge is explored. The maximum value of each dynamic response parameter of the train running in the focused section in this work is compared and analysed. The

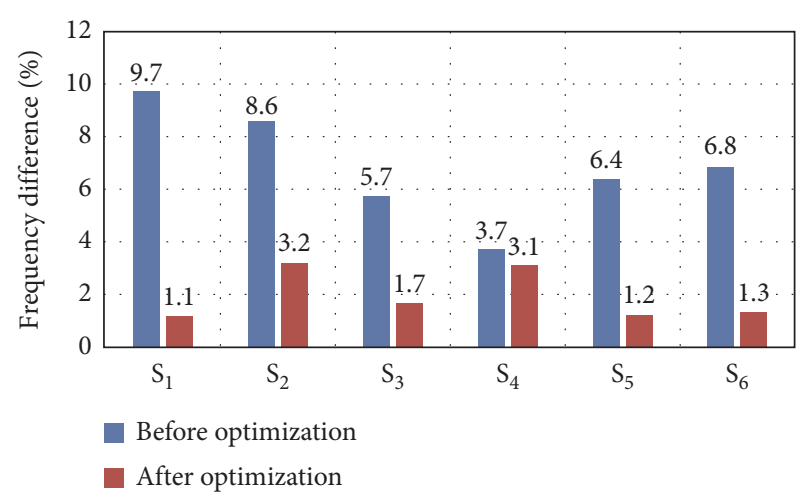

FIgURE 7: Variation of frequency difference before and after optimization.

results of vehicle dynamic response are shown as Figures 10-13.

As can be seen from the figures above, with train speed changing, the dynamic responses of the train are different. As can be seen from Figure 10, when a train is running on 


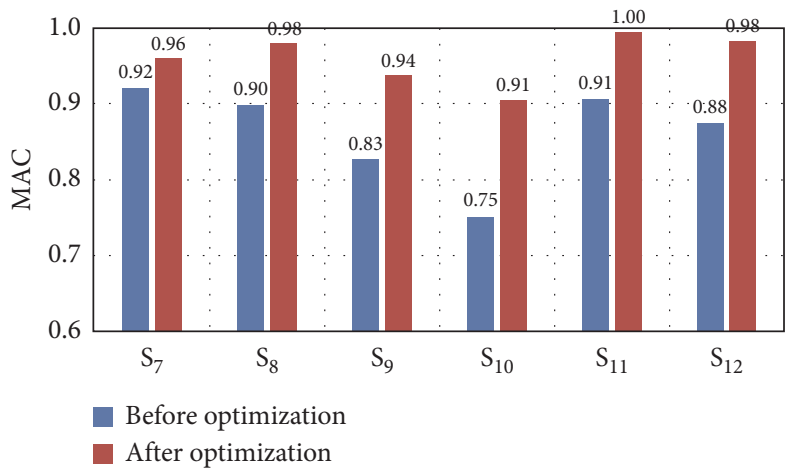

Figure 8: Variation of $M A C$ before and after optimization.

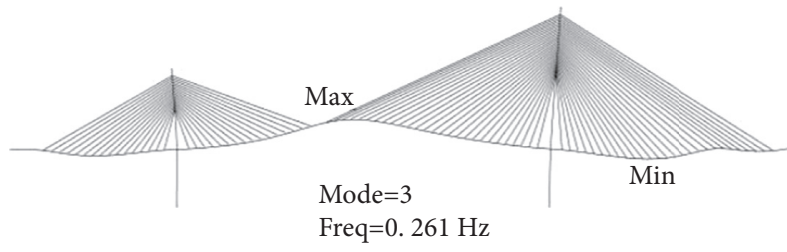

(a)

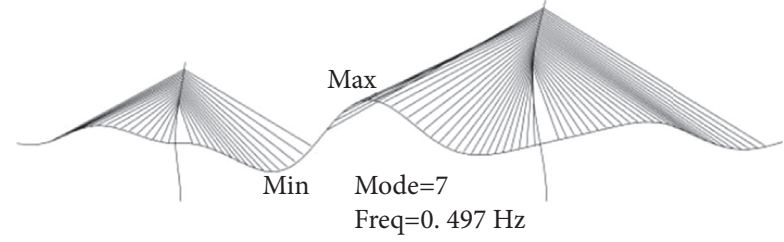

(c)

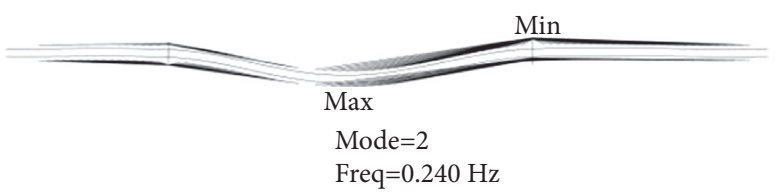

(e)

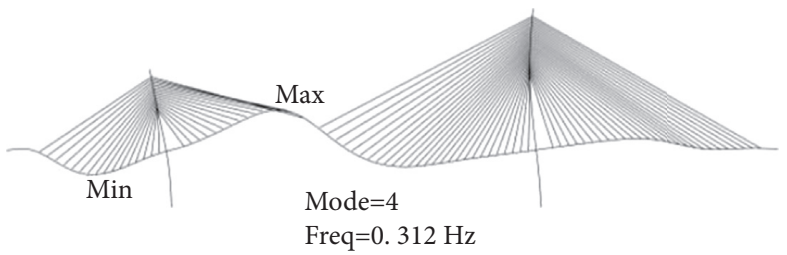

(b)

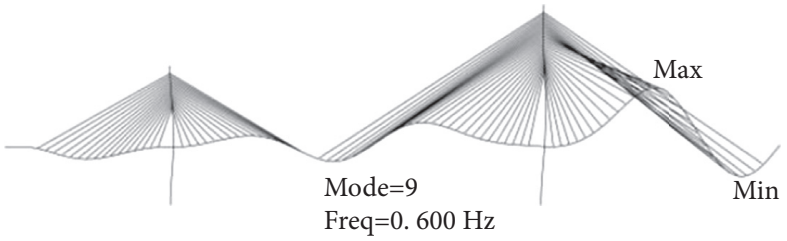

(d)

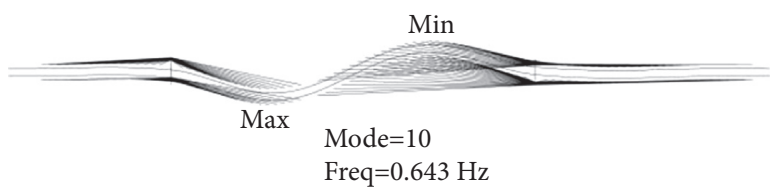

(f)

Figure 9: Key vibration mode of the bridge. (a) First-order vertical vibration mode $(f=0.261 \mathrm{~Hz})$. (b) Second-order vertical vibration mode $(f=0.312 \mathrm{~Hz})$. (c) Third-order vertical vibration mode $(f=0.497 \mathrm{~Hz})$. (d) Fourth-order vertical vibration mode $(f=0.600 \mathrm{~Hz})$. (e) First-order lateral vibration mode $(f=0.240 \mathrm{~Hz})$. (f) Second-order lateral vibration mode $(f=0.643 \mathrm{~Hz})$.

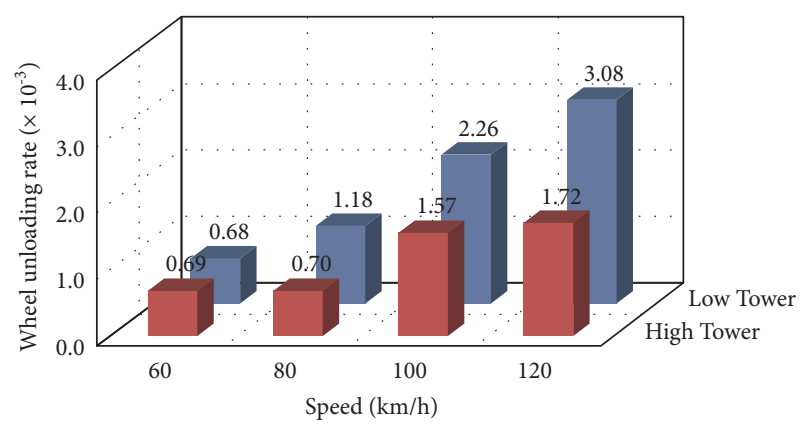

FIGURE 10: Comparison of wheel unloading rate.

the low tower side, its wheel unloading rate is greater than when the train is running on the high tower side. In addition, with train speed increasing, the difference gradually increases. Furthermore, when the train speed is $120 \mathrm{~km} / \mathrm{h}$, the wheel unloading rate on the low tower side can reach nearly twice that on the high tower side. As can be seen from Figure 11, the vertical acceleration of the car body when the train is running on the low tower side is much greater than that of the train when it is running on the high tower side. With train speed increasing, the vertical acceleration difference of car body between the low tower side and the high tower side gradually increases; the vertical acceleration difference of the car body indicates the obvious difference in the stability of the train running on the low tower side and the high tower side, which will directly affect the riding comfort. According to Figures 12 and 13, when the train passes through the bridge, there are some differences in the vertical force of the wheelset and derailment coefficient between the low tower side and the high tower side, but the variation law of the difference is not apparent, and the difference is small on the whole. 


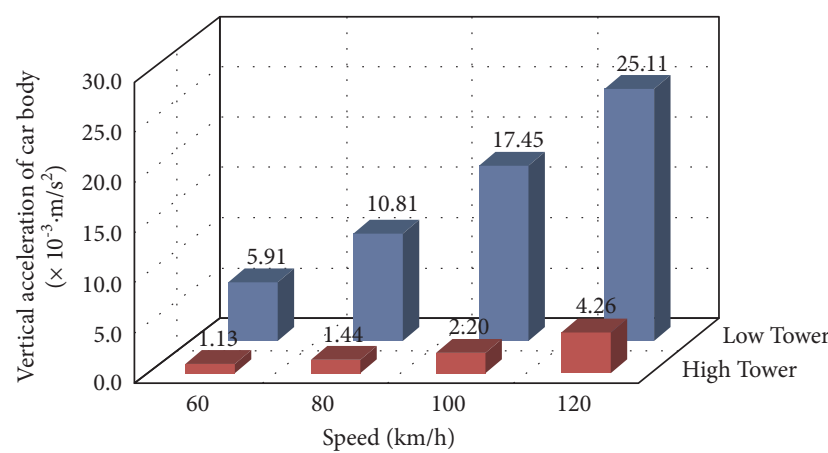

Figure 11: Comparison of vertical acceleration of car body.

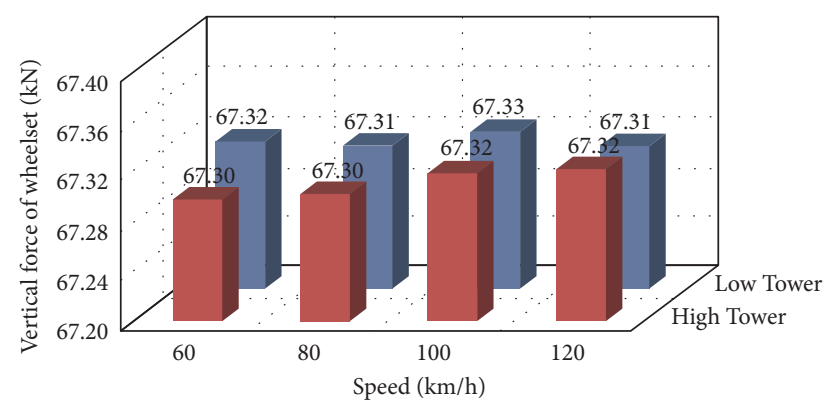

FIgURE 12: Comparison of vertical force of wheelset.

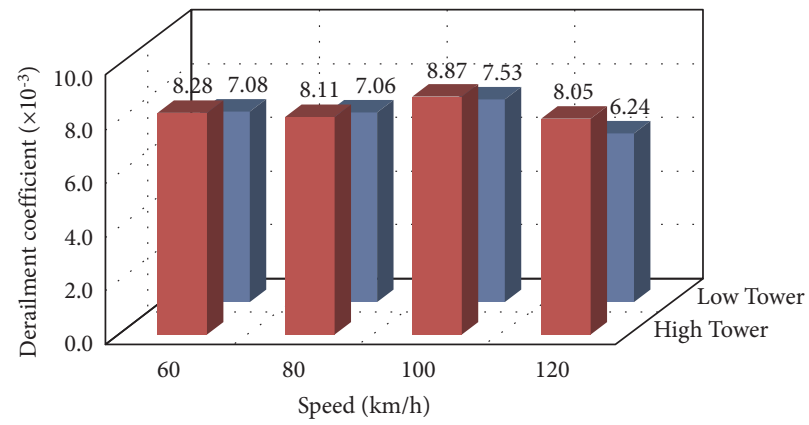

Figure 13: Comparison of derailment coefficient.

4.4. Influence of Stiffness Asymmetry of the Cable-Stayed Bridge on Vibration of the Bridge System. In this section, the dynamic response difference of the main beam between Section-A and Section-B induced by the TCV and its variation laws are studied under different train speeds and at different positions from the bridge tower. The timehistory data of vertical displacement and vertical vibration acceleration at L1-L4 and R1-R4 are collected, respectively. When the train runs across the bridge at the speed of $120 \mathrm{~km} / \mathrm{h}$, the vertical vibration acceleration time-history curves of L1/L4 and R1/R4 are shown in Figures 14 and 15, respectively.

From the comparisons of the two sets of time-history curves, it is found that the trend of the vertical vibration acceleration time-history curves of L1 and L4 is similar under the same train speed and this conclusion can also apply to R1 and R4. In addition, the vertical vibration acceleration of the main beam increases obviously when the

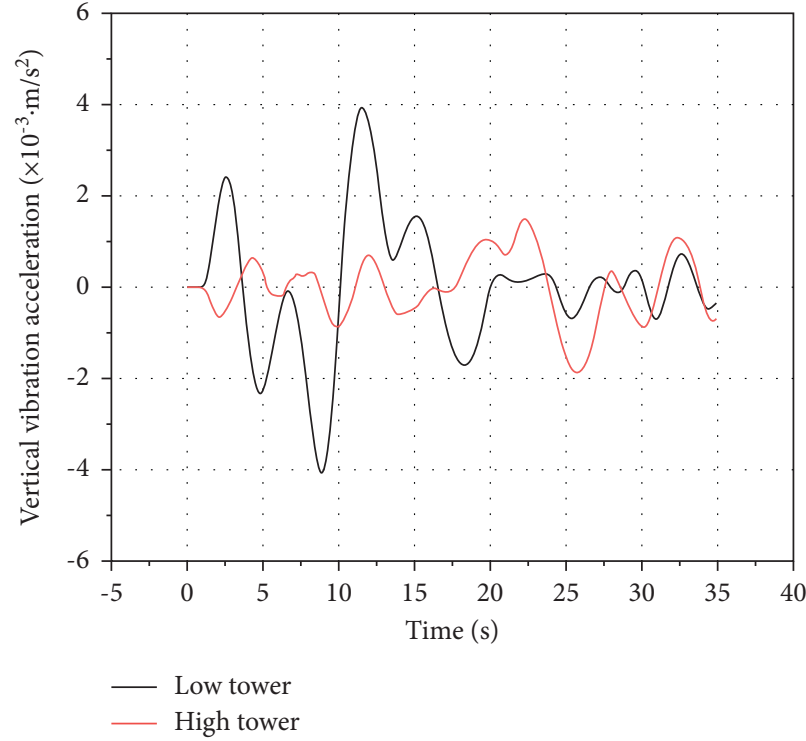

Figure 14: Comparison of vertical vibration acceleration timehistory curves at L1 and R1.

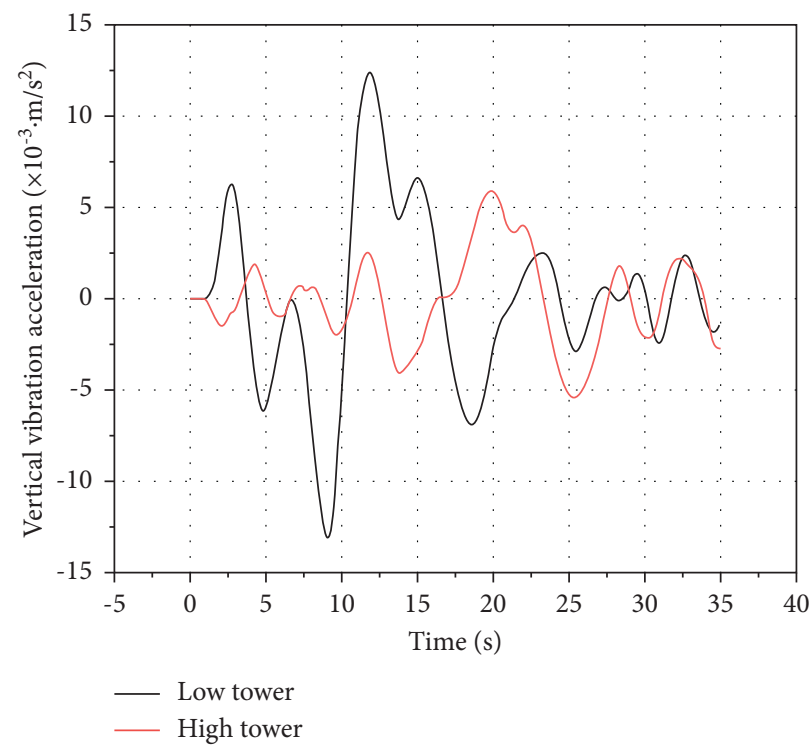

FIgURE 15: Comparison of vertical vibration acceleration timehistory curves at L4 and R4.

observation point is closer to the midpoint of main span, and the maximum value of the vertical vibration acceleration on the low tower side is larger than that on the high tower side under the same operating conditions. Furthermore, as the observation point is gradually away from the bridge tower, the difference of vertical vibration acceleration between the observation points near the high tower side and the observation points near the low tower side also increases obviously.

In order to further analyse the dynamic response of the main beam, the time-domain transformation of the vertical vibration acceleration of the main beam is carried out. The frequency-domain curves are shown in Figures 16 and 17. 


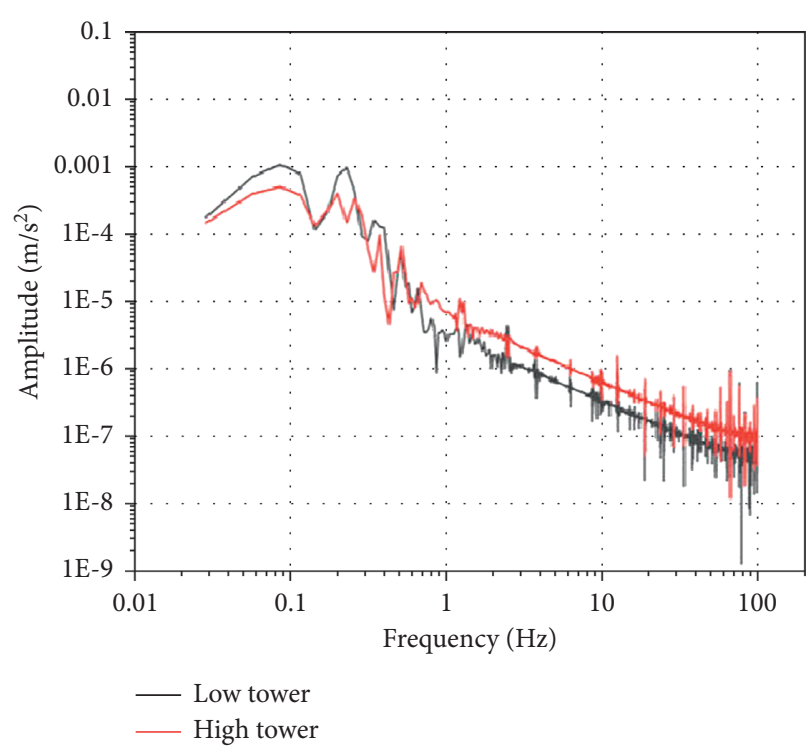

FIGURE 16: Comparison of vertical vibration acceleration frequency-domain curves at L1 and R1.

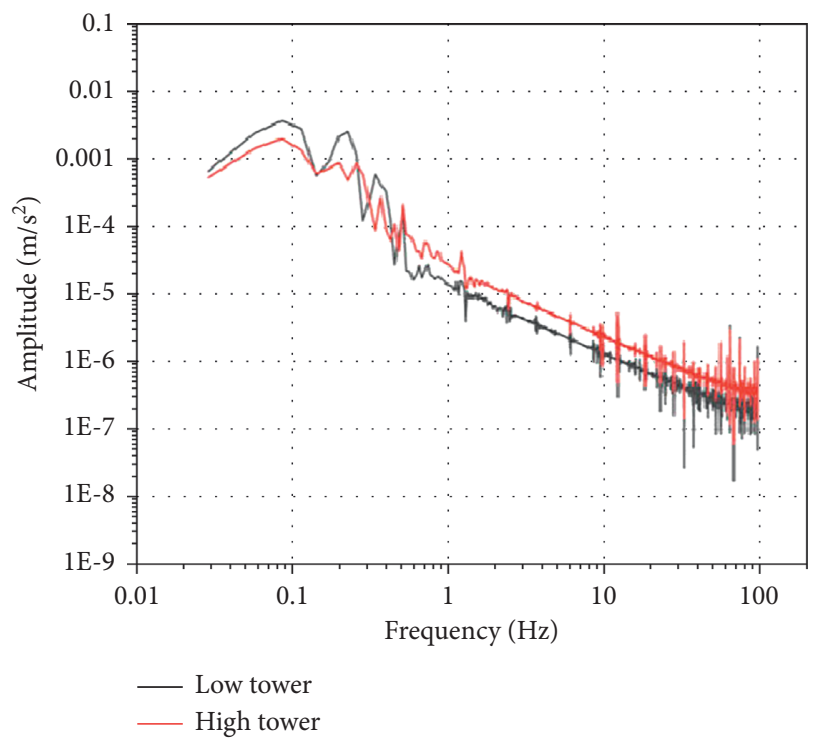

FIGURE 17: Comparison of vertical vibration acceleration frequency-domain curves at L4 and R4.

From the comparisons of the two sets of frequencydomain curves, we can see that under the same train speed, the trend of the vertical vibration acceleration frequencydomain curves of L1/R1 and L4/R4 is similar. When the observation point is far away from the tower, the amplitude of the main beam is obviously larger. From the frequencydomain distribution of the vertical vibration acceleration of the main beam, when the frequency is low $(0.02 \mathrm{~Hz}$ $-0.6 \mathrm{~Hz}$ ), the amplitude of the vertical vibration acceleration of the low tower side is generally greater than that of the high tower side. When the frequency is higher (more than $0.6 \mathrm{~Hz}$ ), the amplitude of vertical vibration acceleration on the high tower side is larger than that on the low tower side.
Figures 18 and 19 show the dynamic responses of L1-L4 and R1-R4 when the train runs through the bridge at different speeds.

When the train travels through the bridge at different speeds, the variation of the dynamic response difference between the observation points near the high tower side and the observation points near the low tower side is further shown in Figures 20 and 21.

The analysis of the above-mentioned dynamic response data shows that under different running speeds, the dynamic response difference of the main beam at the observation points near the low tower and at the observation points near the high tower is significant. Under some operating conditions, the maximum vertical displacement of the observation points on the low tower side is $52 \%$ higher than that on the high tower side, and the maximum vertical vibration acceleration of the low tower side can be $139 \%$ higher than that on the high tower side. According to Figure 20, the vertical displacement difference of the observation points at the same distance from the bridge tower is not obviously fluctuated, which is not changed by the change of the speed. With the increasing distance from the observation points to the tower, the vertical displacement difference increases gradually, and the variation trend of the difference is very obvious. From the analysis of Figure 21, it is found that the vertical vibration acceleration difference of the observation points at the same distance from the bridge tower increases with increasing train speed, while the vertical vibration acceleration difference increases with the distance from the observation point to the bridge tower increasing when the speed of train is the same. Furthermore, the vertical vibration acceleration difference increases significantly with the speed increasing when the observation points are getting far from the tower. In general, the vibration of the main beam on the low tower side is larger than that on the high tower side.

From Figures 20 and 21, it can be seen that there is a mapping relationship between the vertical displacement difference and the distance from the observation point to the bridge tower, while there is also a mapping relationship between the vertical vibration acceleration difference and the train speed and the distance from the observation point to the bridge tower simultaneously. Therefore, in order to describe the mapping relationship accurately, these data of the vertical displacement difference, the vertical vibration acceleration difference, the train speed, and the distance of observation point to bridge tower are nonlinear fitted. According to the law of data distribution, the vertical displacement difference and the vertical vibration acceleration difference are fitted by plane model and surface model, respectively (see Figure 22). In Figure 22, the differences of vertical displacement and vertical vibration acceleration are, respectively, represented by $\Delta z$ and $\Delta a$, while $v$ represents the train speed and $d_{t}$ indicates the distance from the observation point to the bridge tower.

From Figure 22, we can see that there is a mapping relationship between the dynamic response difference and the speed and the position of the observation point, and the nonlinear fitting coefficients have exceeded 0.95. 


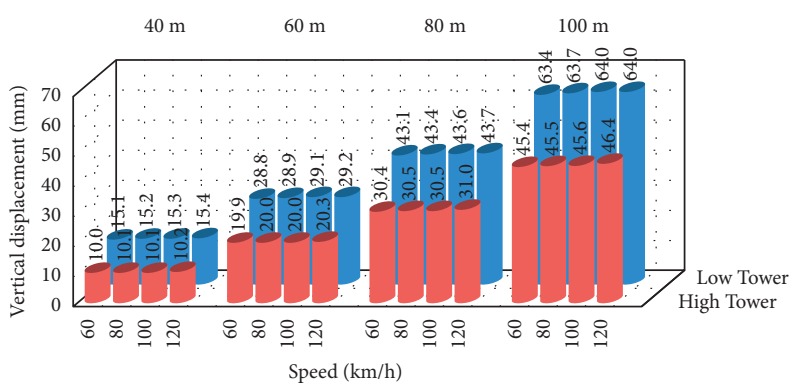

Figure 18: Comparison of vertical displacement.

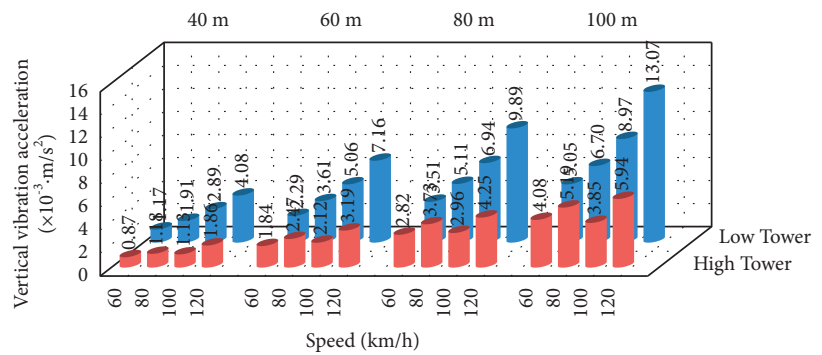

Figure 19: Comparison of vertical vibration acceleration.

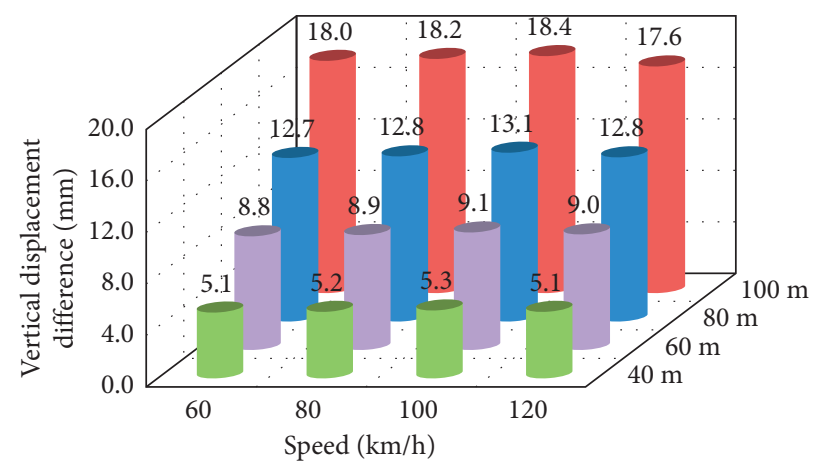

FIGURE 20: The variation trend of the vertical displacement difference.

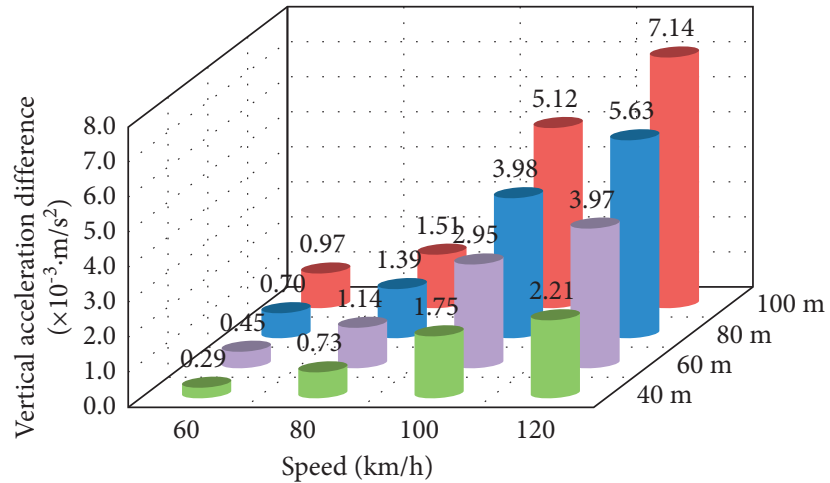

FIgURE 21: The variation trend of the vertical vibration acceleration difference. 


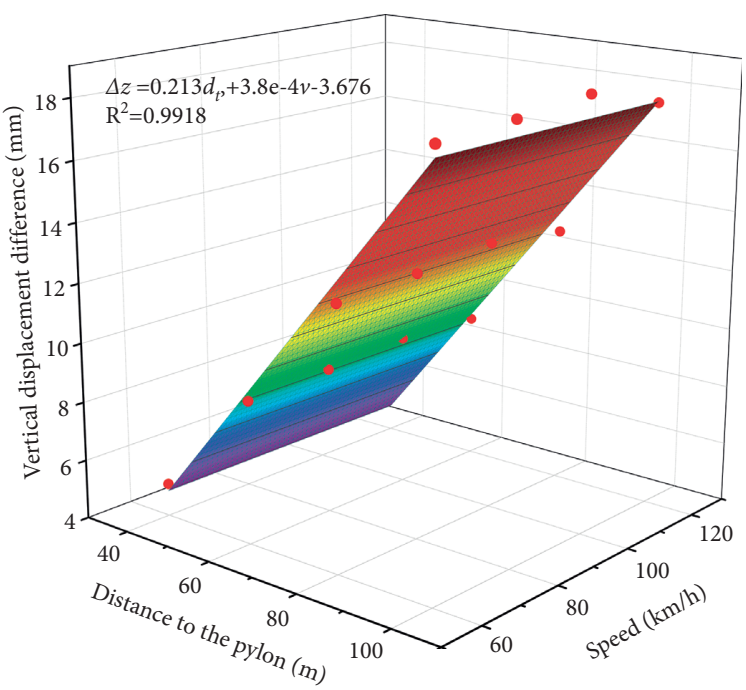

(a)

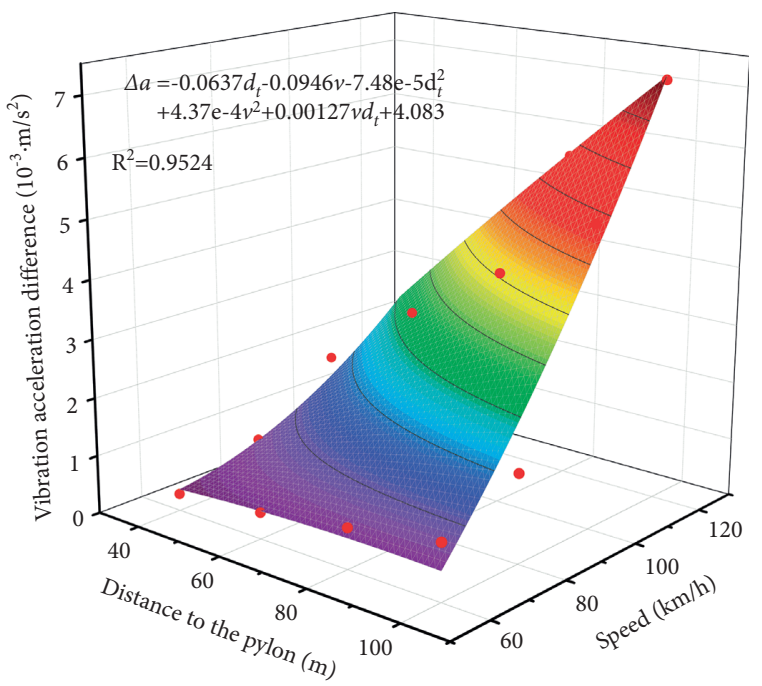

(b)

FIgURE 22: The nonlinear fitting of the dynamic response difference. (a) The vertical displacement difference. (b) The vertical vibration acceleration difference.

$$
\begin{aligned}
& \Delta z=0.213 d_{t}+3.8 e-4 v-3.676 \\
& \Delta a=-0.0637 d_{t}-0.0946 v-7.48 e-5 d_{t}^{2}+4.37 e-4 v^{2}+0.00127 v d_{t}+4.083
\end{aligned}
$$

Based on the above equations, the difference of vertical displacement and vibration acceleration of the main beam on both sides of the bridge can be calculated at different train speeds and at different positions of the bridge, which provides the basis for reasonable distribution of the vertical stiffness along the longitudinal direction of the bridge.

For the UHTCB, the asymmetrical characteristics of its structure will lead to the asymmetry and inhomogeneity of stiffness distribution. Due to the difference of stiffness on both sides of the main span of the bridge, the stress on both sides of the structure is not uniform. As a railway cablestayed bridge in metro lines, under the impact of the train for many years, the problem of nonuniform force on both sides of the bridge is enlarged gradually, which causes further structural fatigue problems, resulting in the reduction of the ultimate bearing capacity of the bridge and accelerating the aging of the bridge. Therefore, this paper can offer useful reference for similar bridge design, which can be used to control the bridge's nonuniform force, and provide reference for bridge's vibration mitigation and operation.

\section{Conclusions}

In this work, primarily, an NMUT based on penalty function theory is proposed, which can be used to optimize the bridge model. Then the TCDM is established on the basis of the TDIT. Finally, a long-span UHTCB is applied as the case to investigate its train-track-bridge dynamic behaviour. From above research, the conclusions can be as follows.

(i) This proposed NMUT is efficacious and practical. After 35 iterations of updating, the modal analysis results of the final updated model are highly consistent with the experimental modal results.

(ii) For the long-span UHTCB, with train speed changing, the dynamic responses of the train are different. Generally speaking, when the train travels through the bridge, the difference of the vertical force of the wheelset and the derailment coefficient has no clear variation law, and the value is small. The difference of the wheel unloading rate and the vertical acceleration of the car body is large and intensifies with the increase of the train speed, which will significantly affect the safety and ride comfort of the train.

(iii) For the long-span UHTCB, there is a significant dynamic response difference of the main beam on both sides of the main span of the bridge. The vertical displacement difference of the main beam on both sides of the main span of the bridge increases with the distance from the observation point to the bridge tower increasing. The variation trend of vertical vibration acceleration difference on both sides of the main span of the bridge will be affected by the speed of the train and the distance from observation point to bridge tower simultaneously. In general, the vibration of the main beam on the low tower side is larger than that on the high tower side.

\section{Data Availability}

No data were used to support this study. 


\section{Conflicts of Interest}

The authors declare that there are no conflicts of interest regarding the publication of this paper.

\section{Acknowledgments}

This work was supported by the National Natural Science Foundation of China (U20A20314), the Innovation Research Groups of the Natural Science Foundation of Chongqing (cstc2019jcyj-cxttX0004), and the Technology Innovation and Application Development Special Key Project of Chongqing (cstc2019jscx-gksbX0047).

\section{References}

[1] Z. W. Chen and W. M. Zhai, "Theoretical method of determining pier settlement limit value for China's high-speed railway bridges considering complete factors," Engineering Structures, vol. 209, Article ID 109998, 2020.

[2] Y. L. Li, X. Y. Xu, Y. Zhou, C. S. Cai, and J. X. Qin, “An interactive method for the analysis of the simulation of vehicle-bridge coupling vibration using ANSYS and SIMPACK," Proceedings of the Institution of Mechanical Engineers-Part F: Journal of Rail and Rapid Transit, vol. 232, no. 3, pp. 663-679, 2016.

[3] H. L. Yu, B. Wang, C. P. Xia, Z. Y. Gao, and Y. L. Li, "Efficient non-stationary random vibration analysis of vehicle-bridge system based on an improved explicit time-domain method," Engineering Structures, vol. 231, Article ID 111786, 2021.

[4] W. M. Zhai, S. L. Wang, N. Zhang et al., "High-speed train-track-bridge dynamic interactions-Part II: experimental validation and engineering application," International Journal of Reality Therapy, vol. 1, no. 1-2, pp. 25-41, 2013.

[5] W. M Zhai, H. Xia, C. B. Cai et al., "High-speed train-track-bridge dynamic interactions-Part I: theoretical model and numerical simulation," International Journal of Reality Therapy, vol. 1, no. 1-2, pp. 3-24, 2013.

[6] J. M. Olmos and M. A. Astiz, "Analysis of the lateral dynamic response of high pier viaducts under high-speed train travel," Engineering Structures, vol. 56, pp. 1384-1401, 2013.

[7] D. Younesian, S. R. Marjani, and E. Esmailzadeh, "Importance of flexural mode shapes in dynamic analysis of high-speed trains traveling on bridges," Journal of Vibration and Control, vol. 20, no. 10, pp. 1565-1583, 2013.

[8] J. D. Yau, M. D. Martínez-Rodrigo, and A. Doménech, "An equivalent additional damping approach to assess vehiclebridge interaction for train-induced vibration of short-span railway bridges," Engineering Structures, vol. 188, pp. 469-479, 2019.

[9] P. Antolín, N. Zhang, J. M. Goicolea, H. Xia, M. A. Astiz, and J. Oliva, "Consideration of nonlinear wheel-rail contact forces for dynamic vehicle-bridge interaction in high-speed railways," Journal of Sound and Vibration, vol. 332, no. 5, pp. 1231-1251, 2013.

[10] L. R. Ticona Melo, D. Ribeiro, R. Calçada, and T. N. Bittencourt, "Validation of a vertical train-track-bridge dynamic interaction model based on limited experimental data," Structure and Infrastructure Engineering, vol. 16, no. 1, pp. 181-201, 2019.

[11] Z. H. Zhu, W. Gong, L. D. Wang, I. E. Harik, and Y. Bai, "A hybrid solution for studying vibrations of coupled train-track- bridge system," Advances in Structural Engineering, vol. 20, no. 11, pp. 1699-1711, 2017.

[12] Q. Zeng, C. D. Stoura, and E. G. Dimitrakopoulos, "A localized Lagrange multipliers approach for the problem of vehicle-bridge-interaction," Engineering Structures, vol. 168, pp. 82-92, 2018.

[13] Z. W. Chen and H. Fang, "An alternative solution of traintrack dynamic interaction," Shock and Vibration, vol. 2019, Article ID 1859261, 14 pages, 2019.

[14] L. Xu and W. M. Zhai, "A three-dimensional model for traintrack-bridge dynamic interactions with hypothesis of wheelrail rigid contact," Mechanical Systems and Signal Processing, vol. 132, pp. 471-489, 2019.

[15] X. Han, H. Y. Xiang, Y. L. Li, and Y. C. Wang, "Predictions of vertical train-bridge response using artificial neural networkbased surrogate model," Advances in Structural Engineering, vol. 22, no. 12, pp. 2712-2723, 2019.

[16] L. F. Xin, X. Z. Li, J. X. Zhang, Y. Zhu, and L. Xiao, "Resonance analysis of train-track-bridge interaction systems with correlated uncertainties," International Journal of Structural Stability and Dynamics, vol. 20, no. 1, Article ID 2050008, 2020.

[17] J. F. Mao, Z. W. Yu, and L. Z. Jiang, "Stochastic analysis of vehicle-bridge coupled interaction and uncertainty bounds of random responses in heavy haul railways," International Journal of Structural Stability and Dynamics, vol. 19, no. 12, Article ID 1950144, 2019.

[18] Z. B. Jin, B. Huang, S. L. Pei, and Y. J. Zhang, "Energy-based additional damping on bridges to account for vehicle-bridge interaction," Engineering Structures, vol. 229, Article ID 111637, 2021.

[19] P. Bussetta, S. B. Shiki, and S. D. Silva, "Nonlinear updating method: a review," Journal of the Brazilian Society of Mechanical Sciences and Engineering, vol. 39, no. 11, pp. 47574767, 2017.

[20] W. X. Ren and H. B. Chen, "Finite element model updating in structural dynamics by using the response surface method," Engineering Structures, vol. 32, no. 8, pp. 2455-2465, 2010.

[21] Y. Liu and Z. D. Duan, "Fuzzy finite element model updating of bridges by considering the uncertainty of the measured modal parameters," Science China Technological Sciences, vol. 55, no. 11, pp. 3109-3117, 2012.

[22] S. Chakraborty and A. Sen, "Adaptive response surface based efficient finite element model updating," Finite Elements in Analysis and Design, vol. 80, pp. 33-40, 2014.

[23] E. Asgarieh, B. Moaveni, and A. Stavridis, "Nonlinear finite element model updating of an infilled frame based on identified time-varying modal parameters during an earthquake," Journal of Sound and Vibration, vol. 333, no. 23, pp. 6057-6073, 2014.

[24] R. Astroza, L. T. Nguyen, and T. Nestorović, "Finite element model updating using simulated annealing hybridized with unscented Kalman filter," Computers \& Structures, vol. 177, pp. 176-191, 2016.

[25] X. Wang, T. L. Hill, S. A. Neild, A. D. Shaw, H. H. Khodaparast, and M. I. Friswell, "Model updating strategy for structures with localised nonlinearities using frequency response measurements," Mechanical Systems and Signal Processing, vol. 100, pp. 940-961, 2018.

[26] Y. X. Pan, C. E. Ventura, H. B. Xiong, and F. L. Zhang, "Model updating and seismic response of a super tall building in Shanghai," Computers \& Structures, vol. 239, Article ID 106285, 2020. 
[27] A. Jayswal and P. Kardam, "An exact 11 penalty function method for multi-dimensional first-order PDE constrained control optimization problem," European Journal of Control, vol. 52, pp. 34-41, 2020.

[28] Z. W. Chen, W. M. Zhai, C. B. Cai, and Y. Sun, "Safety threshold of high-speed railway pier settlement based on train-track-bridge dynamic interaction," Science China Technological Sciences, vol. 58, no. 2, pp. 202-210, 2015. 